\title{
Evaluation of a simple colorimetric analysis for urinary malondialdehyde determination
}

This article was published in the following Dove Press journal:

Pathology and Laboratory Medicine International

6 January 2010

Number of times this article has been viewed

\author{
A Suha Yalçın ${ }^{1,2}$ \\ Ahmet Kılınç² \\ Burak Cöbek ${ }^{2}$ \\ 'Department of Biochemistry, School \\ of Medicine, Marmara University, \\ Haydarpașa-İstanbul Turkey; ${ }^{2}$ Oksante \\ R\&D Laboratory, GOSB Teknopark, \\ Gebze-Kocaeli, Turkey
}

\begin{abstract}
Oxidative stress results when the amount of free radical formation exceeds the capacity of the antioxidant defense system. It is related to a number of pathological conditions including: cardiovascular disease, neurodegenerative disease, cancer, diabetes mellitus, gastrointestinal system disorders, inflammation and aging. It is difficult to quantify free radicals directly due to their reactive nature and short half-life. For this reason, most people prefer to measure antioxidant levels and/or the end products of free radical attack on macromolecules such as lipids, proteins and nucleic acids. In this study we have established a short and easy method to determine urinary levels of malondialdehyde, an end product of lipid peroxidation. The method depends on the spectroscopic measurement of color intensity of the product formed by the reaction of the aldehyde groups with the Schiff reagent. The method is linear at a concentration range of $1-10 \mu \mathrm{M}$ and correlates with the widely used thiobarbituric acid method.
\end{abstract}

Keywords: urinary malondialdehyde, oxidative stress, Schiff reagent

\section{Introduction}

Free radicals and reactive oxygen species are continuously produced during cellular metabolism. ${ }^{1,2}$ These are highly reactive electrophilic oxidant species which attack surrounding molecules. Overproduction of these reactive species results in oxidative stress, a condition in which the accumulation of free radicals exceeds the antioxidant capacity. Oxidative stress is related to a number of pathological conditions including cardiovascular disease, neurodegenerative disease, cancer, diabetes mellitus, gastrointestinal system disorders, inflammation and aging. ${ }^{3}$

It is difficult to quantify free radicals directly due to their short half-life and high reactivity. Instead, it is preferred to determine their "footprint" after attacking cellular components such as lipids, proteins and DNA. Lipid peroxidation is a free radical mediated chain of reactions that results in the oxidative breakdown of polyunsaturated fatty acids. ${ }^{4}$ The initial products formed are lipid peroxides which tend to degrade rapidly to form a variety of secondary products. ${ }^{5}$ Many different methods have been developed to assess the level of lipid peroxidation by measuring a variety of sub-products including: conjugated dienes, volatile gases such as ethane and pentane, isoprostanes, and aldehydes such as 4-hydroxynonenal and malondialdehyde. ${ }^{5,6}$ Other methods measuring oxidative damage to protein and DNA are also available. ${ }^{7,8}$

Measurement of malondialdehyde (MDA) is by far the most popular indicator of oxidative damage to cells and tissue. ${ }^{5} \mathrm{MDA}, \mathrm{CH}_{2}(\mathrm{CHO})_{2}$ is produced from the breakdown of polyunsaturated fatty acids. In the past 20 to 25 years, MDA has been
Correspondence: A Suha Yalçın Department of Biochemistry, School of Medicine, Marmara University, 34668, Haydarpașa-İstanbul,Turkey

Tel +902164144733

Fax +902164181047

Email asyalcin@marmara.edu.tr
Pathology and Laboratory Medicine International 2010:2 23-26

(c) 20IO Yalçın et al, publisher and licensee Dove Medical Press Ltd. This is an Open Access article which permits unrestricted noncommercial use, provided the original work is properly cited. 
recognized as an important indicator of lipid peroxidation and oxidative stress-related disease states. ${ }^{9,10}$

The Schiff test, devised by Hugo Schiff, is a chemical test for the detection of aldehydes ${ }^{11}$. In this study, we have established a simple colorimetric analysis based on the Schiff reagent for the quantification of urinary malondialdehyde.

\section{Materials and methods}

\section{Subjects, chemicals and standards}

Spot urine samples were collected in the morning from apparently healthy individuals ( $\mathrm{n}=218,114$ male, 104 female) aged 1 to 80 years. Basic fuchsin and methanol (HPLC Grade) was obtained from Merck. Malondialdehyde bis(diethyl acetal), sodium metabisulfite, phosphoric (V) acid and thiobarbituric acid was obtained from Sigma-Aldrich. All other chemicals used were of the purest grade commercially available. Malondialdehyde (MDA) standard solution (5 mM) was prepared and diluted with $0.1 \mathrm{M} \mathrm{HCl}$. The solution was hydrolyzed for 3 hours at room temperature. Serial dilutions $(1-10 \mu \mathrm{M})$ were made and used as standards. The concentration of MDA was verified by spectrophotometry at $245 \mathrm{~nm}$ $\left(\varepsilon=13,700 \mathrm{M}^{-1} \mathrm{~cm}^{-1}\right)$.

\section{Colorimetric assay}

Schiff reagent was prepared by dissolving $10 \mathrm{~mL}$ phosphoric (V) acid, $10 \mathrm{~g}$ sodium metabisulfite and $5 \mathrm{~g}$ basic fuchsin in $1 \mathrm{~L}$ of ultra pure water. The mixture was left for 2 hours in the dark before $30 \mathrm{~g}$ of activated carbon was added. The solution was set aside for 24 hours and filtered before use. The colorimetric assay was carried out by adding $20 \mu \mathrm{L}$ of urine to $970 \mu \mathrm{L}$ of ultra-pure water. After thorough mixing $10 \mu \mathrm{L}$ of the Schiff reagent was added and the absorbance at $545 \mathrm{~nm}$ was read within 2 to 5 minutes.

\section{HPLC method}

For the quantification of urinary MDA by HPLC, ${ }^{12,13}$ to $3.0 \mathrm{~mL}$ (1\%) phosphoric (V) acid and $0.4 \mathrm{ml}$ ultra pure water $0.6 \mathrm{~mL}$ of sample or standard (1-10 $\mu \mathrm{M}$ MDA) was added to a screw capped test tube and mixed thoroughly. Then, $1.0 \mathrm{~mL}$ of $0.67 \%$ thiobarbituric acid was added to all tubes and kept in a boiling water bath for 1 hour. After chilling in crushed ice, the tubes were centrifuged at $14,000 \times \mathrm{g}$ for 15 minutes. The supernatant was filtered before being applied to a C-18 column. Measurements were made with a UV-Vis detector at $532 \mathrm{~nm}$. Mobile phase was $0.05 \mathrm{M}$ potassium phosphate buffer ( $\mathrm{pH} 6.8)$ with methanol $(50: 50, \mathrm{v} / \mathrm{v})$. The flow-rate was $0.5 \mathrm{~mL} / \mathrm{min}$.

\section{Statistical analysis}

Statistical analysis was carried out using the Student's t-test and the differences were considered to be significant at $P<0.05$.

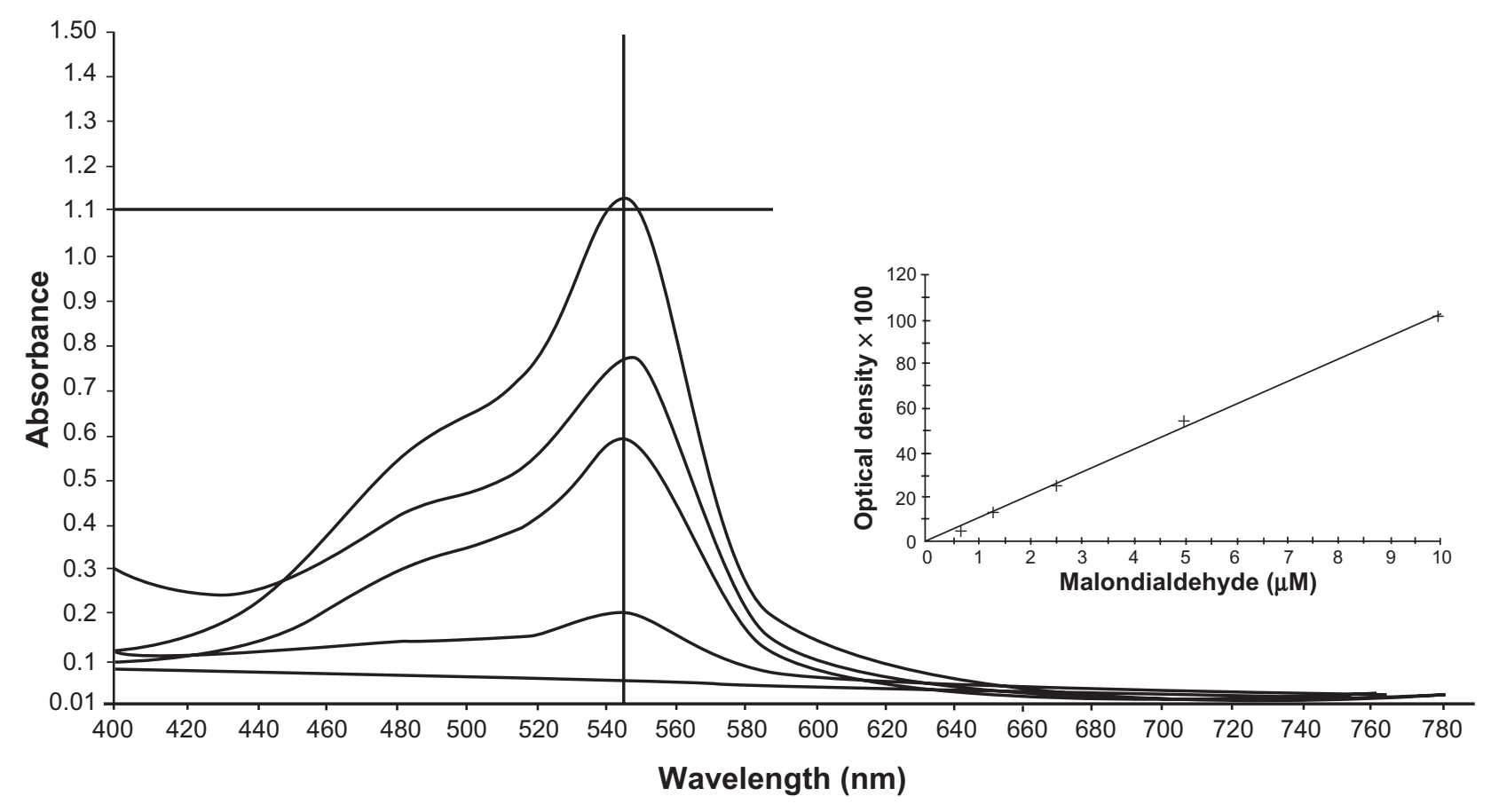

Figure I Absorption curve obtained by the Schiff method at different malondialdehyde concentrations. 
Table I Mean, standard deviation and variances of within-day measurements $(n=10)$ of low and high absorbance samples

\begin{tabular}{llll}
\hline & Mean & Standard deviation & Variance \\
\hline \multicolumn{2}{l}{ Low absorbance } \\
Sample I & 0.030 & 0.006 & 0.00007 \\
Sample 2 & 0.025 & 0.005 & 0.00005 \\
Sample 3 & 0.028 & 0.009 & 0.00009 \\
High absorbance & & \\
Sample I & 0.251 & 0.084 & 0.00798 \\
Sample 2 & 0.382 & 0.132 & 0.01935 \\
Sample 3 & 0.296 & 0.101 & 0.01137 \\
\hline
\end{tabular}

\section{Results and discussion}

It is well known that thiobarbituric acid is a useful general reagent for the determination of MDA as an index of lipid peroxidation. ${ }^{5,10}$ In recent years, methods based on HPLC have been developed for measuring MDA in urine and other body fluids. ${ }^{12-15}$ The use of HPLC with UV-Vis detection has improved the selectivity and sensitivity of the method. However, the method is not practical enough for a large number of samples and requires expensive equipment together with skillful personnel.

Figure 1 shows the absorption curve obtained by the colorimetric Schiff method. The absorbance at $545 \mathrm{~nm}$ was a linear function of the MDA concentration over the range from $0.5 \mu \mathrm{M}$ to $10 \mu \mathrm{M}$. Table 1 summarizes the precision of the method determined by measuring low and high absorbance samples. Within day values are presented with their average, standard deviation and variances. It was observed that the standard deviation and variances of high absorbance samples was much higher than low absorbance samples indicating that at high concentrations of MDA the reliability of the test is low. Figure 2 shows the correlation between the colorimetric Schiff method and the HPLC method.

We have tested the colorimetric Schiff assay in 218 individuals, from both sexes aged between 1 to 80 years. There was no significant difference between values obtained from males and females as well as different age groups. But the distribution of the Schiff assay values showed that more than $70 \%$ of the individuals had an absorbance value that was lower than 0.200 corresponding to $<4$ mM MDA (Figure 3). This value is in agreement with a previous report that studied the stability and intra-individual variation of urinary malondialdehyde. ${ }^{15}$ Thus, we suggest this as a cut-off value for using this simple method as a screening test that may be adapted by small scale laboratories for routine monitoring of oxidative stress. The ability to simultaneously process many samples, ease of use and the rapidity of the method

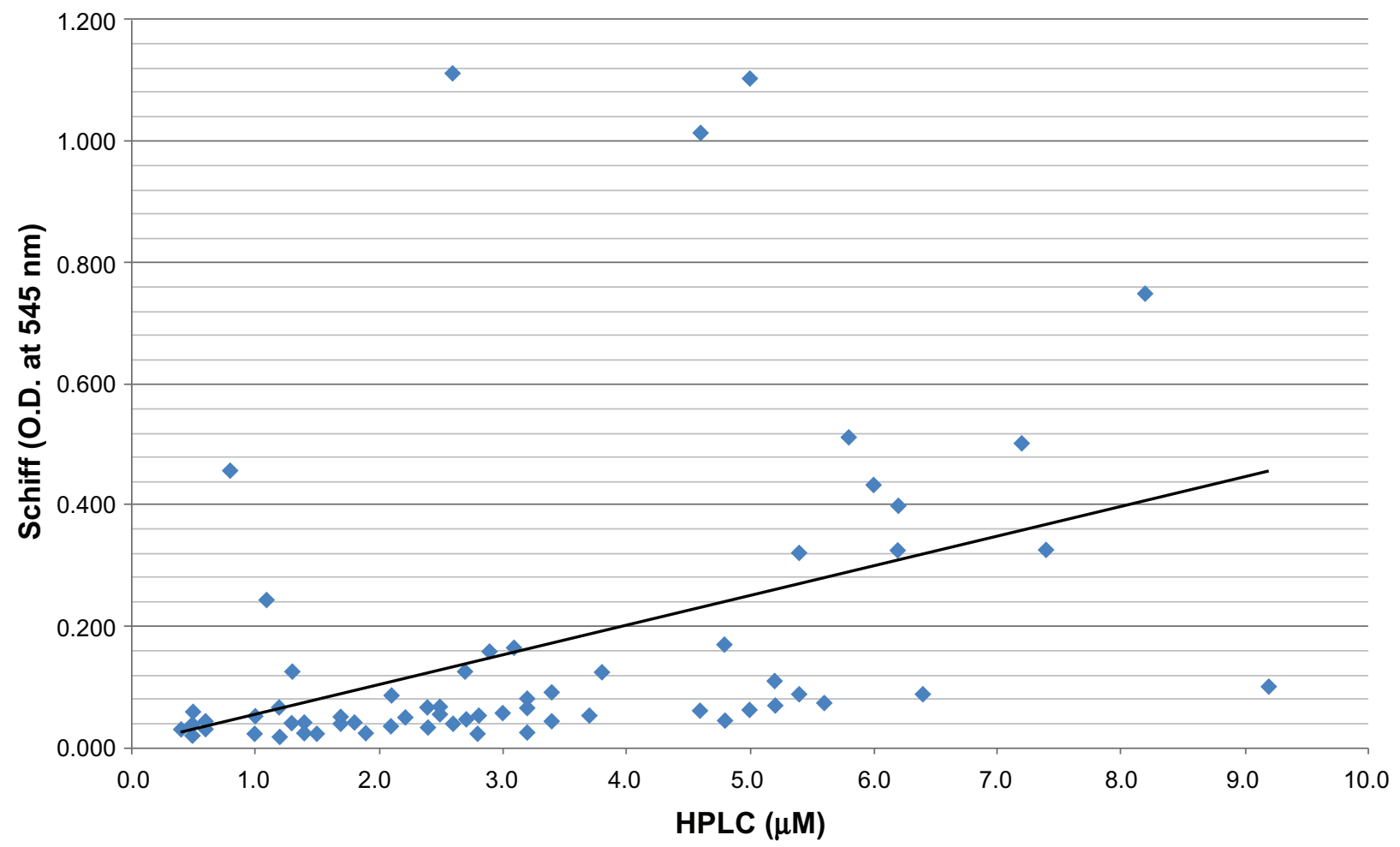

Figure 2 Comparison of the colorimetric Schiff assay results with the HPLC method. 


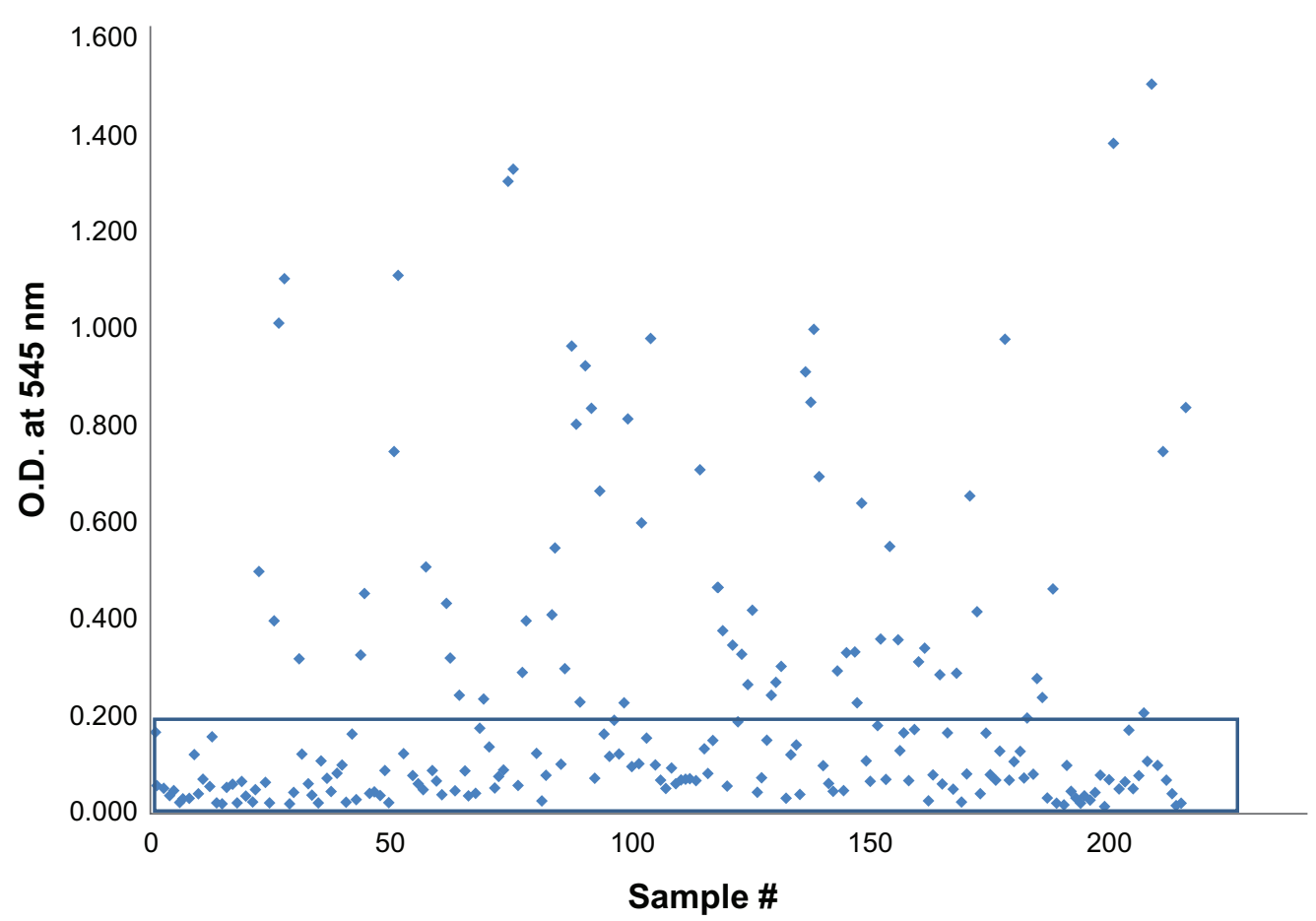

Figure 3 Distribution of colorimetric Schiff assay values in 218 individuals aged I to 80 years.

are practical reasons for supporting its use in the screening of free radical related human disorders.

\section{Acknowledgment}

Supported in part by the Turkish Scientific and Technological Research Council (TUBITAK-TEYDEB, Project no. 7070041). This work was first presented at the 20th National Biochemistry Congress, 29 October-1 November 2008, Kapadokya-Nevşehir, Turkey.

\section{References}

1. Cheeseman KH, Slater TF. An introduction to free radical chemistry. Br Med Bull. 1993;49:281-493.

2. Halliwell B, Gutteridge JMC. Free Radicals in Biology and Medicine. Oxford: Clarendon Press; 1985.

3. Cross CE, Halliwell B, Borish ET. Oxygen radicals and human disease. Ann Intern Med. 1987;107:526-545.

4. Buege J, Aust S. Microsomal lipid peroxidation. Methods Enzymol. 1978;52:302-310.

5. Draper HH, Hadley M. Malondialdehyde determination as index of lipid peroxidation. Methods Enzymol. 1990;186:421-431.
6. Pryor WA, Godber SS. Non-invasive measure of oxidative status in humans. Free Radic Biol Med. 1991;10:177-184.

7. Schachter E. Quantification and significance of protein oxidation in biological samples. Drug Metab Rev. 2000;32:307-326.

8. Ravanat JL. Measuring oxidized DNA lesions as biomarkers of oxidative stress: an analytical challenge. FABAD J Pharm Sci. 2005;30:100-113.

9. Gil P, Fannias F, Casado A, Lopez-Fernandez E. Malondialdehyde: a possible marker of ageing. Gerontology. 2002;48:209-214.

10. Grotto D, Maria LC, Valentin J, et al. Importance of lipid peroxidation biomarkers and methodological aspects for malondialdehyde quantification. Quim Nova. 2009;32:169-174.

11. Schiff H. Eine neue Reihe organischen Diaminen. Justus Liebigs Ann der Chemie. 1866;140:92-137.

12. Korchazhkina O, Exley C, Spencer SA. Measurement by reversed-phase HPLC of MDA in normal human urine following derivatisation with 2,4-DNPH. J Chromatogr B. 2003;794:353-362.

13. Mendes R, Cardoso C, Pestana C. Measurement of malondialdehyde in fish: a comparison study between HPLC methods and the traditional spectrophotometric test. Food Chem. 2009;112:1038-1045.

14. Seljeskog E, Hervig T, Mansoor MA. A novel HPLC method for the measurement of thiobarbituric acid reactive substances (TBARS). Clin Biochem. 2006;39:947-954.

15. Lee KH, Kang D. Stability and intra-individual variation of urinary malondialdehyde and 2-naphthol. J Prev Med Public Health. 2008; 41:195-199.
Pathology and Laboratory Medicine International

\section{Publish your work in this journal}

Pathology and Laboratory Medicine International is a peer-reviewed, open access journal focusing on innovative basic research and translational research related to pathology or human disease. The journal includes original research, updates, case reports, reviews and commentaries on current controversies. The Academic Sponsor

\section{Dovepress}

of this journal is the Chinese American Pathology Association (CAPA). The manuscript management system is completely online and includes a very quick and fair peer-review system. Visit http://www.dovepress.com/testimonials.php to read real quotes from published authors. 